\title{
LAUDATIO Y SUASIO EN EL PRO MARCELLO
}

\author{
ELISABETH CABALLERO DE DEL SASTRE - Universidad de Buenos Aires \\ ALICIA SCHNIEBS DE ROSSI - Universidad de Buenos Aires \\ BEATRIZ RABAZA - Universidad Nacional de Rosario \\ DARIO MAIORANA - Universidad Nacional de Rosario
}

\begin{abstract}
Resumo: A crfica costuma considerar o Pro Marcello como um obséquio de Clcero ante César e, portanto, costuma inscrevê-lo no genus demonstrativum. A análise deste discurso pemite demonstrar que laudatio Caesaris é um recurso destinado a captar a atençáo e a benevolência de César. Portanto, o discurso está inscrito no ámbito do genus deliberativum e, dentro dele, na suasio. O conteúdo e organização dessa suasio respondem à estreita e indissolúvel vinculaçăo que, no pensamento de Clcero, tem o seu officio de orador, de homem polftico e de pensador.
\end{abstract}

"Neque sane iam causa videtur esse cur secernamus ea praecepta, quae de suasionibus tradenda sunt aut laudationibus, sunt enim pleraque communia, sed tamen suadere aliquid aut dissuadere gravissimae mihi personae videtur esse; nam et sapientis est consilium explicare suum de maximis rebus et honesti e diserti, ut mente providere, auctoritate probare, oratione persuadere possis".

Cicerón. De Oratore $\| 81,333^{1}$

La retórica ciceroniana se nutre de una complicada simbiosis entre política y filosofla. Esta sintesis aúna el neto pragmatismo romano al estudio del officium del orador, según una mezcla de ideas filosoficas.

1 - Esta cita ha sido elegida como epigrafe en virtud de que consideramos que confirma la hipótesis de nuestro trabajo, no sólo en lo que hace a la relación suasio/laudatio, sino también al juego dialéctico entre filosofia, polf́tica y retórica. La "gravissimae personae", designación cargada del peso ético-social de la gravitas, a quiem se le atribuyen las acciones de suadere y dissuadere, es desde luego el orator. Sobre él se predica, por medio de una compleja combinación de dos isocola, de tres miembros que se correspondem uno a uno. Asf, la condición de sapiens, le permite al orador "mente provide$\mathrm{re}^{\prime}$, la de honestus, le permite "auctoritate probare", y la de disertus, le permite "oratione persuadare". Aparece aqul el ideal estoico del sabio indisolúblemente unido a la posesión de la virtus y a su condición de honestus. Asł, dice Cicerón en Del officiis III 3,13: "Atque illud quidem honestum propie vereque dicitur, id in sapientibus est solis neque a virtute divelli umquam potest. in iis autem, in quibus sapientia perfecta non est, ipsum illud quidem perfectum, honestum nullo modo, similitudines honesti esse possunt."

En cuanto al disertus, remite a una cualidad propia del orator. En el primer libro del De Oratore. Cicerón hace una diterencia entre disertus y eloquens pues dice: "scripsi... disertos cognosse me non nullos, eloquentem ad huc neminem, quod eum statuebam disertum qui posset satis acute atque dilucide apud mediocris homines ex communi quadam opinione hominum dicere, eloquentiam vero qui mirabilius et magnificentius augere posset atque ornare quae vellet, omnisque omnium rerum, quae ad dicendum pertinerent, fontis animo ac memoria contineret." (I 21,94). Es importante destacar aqul el acento puesto en el augere y el ornare como elementos distintivos de la eloquentia, del orator en el cual se unen el conocimiento y la estética, como claramente lo dice Cicerón en sus Disputationes Tusculanae: "Hanc enim perfectam philosophlam semper ludicavit quae de maximis quaestionibus coplose posset ornateque dicere" $(14,7)$. Toma la elocuencia una finalidad abarcadora que, como dice Jean Perret (Perret, 1946, D. 181) es uno de los rasgos mas caracteristicos de la itsionomla de Clcerón orador, filósofo y teórico de la elocuencia. Para este tema, ver también Cicerón. De Or. III 35, 143; Fat. II 3; Off. 1 44,156). Surla interesante analizar este pensamiento ciceronlano a la luz del estoicismo medio, que se inaugura con la figura de Panecio, quien fue el primero en valorizar al "hombre estético". Al respecto remitimos a Max Pohlenz (Pohlenz, 1967, p. 400), quiem, a propósito de Panecio afirma que, para este "Tuomo non solo e diverso dalranimale a causa del logos conoscente, ma e anche Punico essere che, uniendo el logos con un corpo ad esso adeguato, diventa capace di cogliere medlanti gli organi di senso il mondo del bello e di plasmare egli stesso con le prople mani delle cose belle. II suo vero, pecullare vantaggio di fronte ali animale consiste nel fatto che egli fonde la conoscenza ragionale con la sensibilita stetica e la creatività artística." Cfr. Cic. Fin. V 14 y el comentario de A. Michel (Michel, 1984, p. 128-142). Es preciso aclarar que el centrarmos en la opinión de Pohlenz no significa dejar de lado la influencia que tuvo Posidonio de Apamea en la obra de Ciceron, pero es un tema que trasciende los límites de esta comunicación (Cir. Marle Laffranque, 1964). 
El Pro Marcello ha sido generalmente considerado como un acto de la obsecuencia ciceroniana ante el vencedor de Farsalia y suele inscribirselo dentro del genus demonstrativum, en función de que se lo considera un elogio de César. Sin embargo, el genero epidíctico no ha sido en Cicerón, como bien lo señala Mme. de Guillemin (Guillemin, 1955, p. 217 ss.), cultivado de manera aislada, sino que, a partir del rol de la oratoria en Roma, es más bien un recurso del ornatus. El análisis que efectuaremos del Pro Marcello, nos permitirá demonstrar que efectivamente la laudatio Caesaris no es en esa oratio sino un recurso destinado a captar la atención y benevolencia del destinatario, Cesar, ante un discurso que se inscribe dentro del genus deliberativum y, dentro de él, en la suasio ${ }^{2}$. A su vez, mostraremos que el contenido y organización de esa suasio responde a esa estrecha e indisoluble vinculación que, dentro del pensamiento ciceroniano, tienen su oficio de orador, de hombre político y de pensador.

Para ello, creemos conveniente, antes de entrar en el análisis del texto, recordar algunas caracteristicas de este genus deliberativum ${ }^{3}$. Son officia propios de este genus la suasio y la dissuasio. Por su propia naturaleza, el momento temporal al que se refieren los asuntos del genus es el futuro, para cuyo conocimiento pueden también tratarse asuntos del pasado y del presente que nos ayudan a conocer el futuro ${ }^{4}$. En lo que se refiere a los afectos, los principales son a spes y el metus ${ }^{5}$. El caso modelo y denominativo es el discurso polftico en el que el orador aconseja o desaconseja una acción futura y lo hace en función de la alternativa utile/inutile, propia de este genus ${ }^{6}$. La oración que abre el Pro Marcello: "Diuturni silenti, patres conscripti, quo eram his temporibus usus - non timore aliquo, sed partim dolore, partim verecundia filem hodiernus dies attulit, idemque initum quae vellem quaeque sentirem meo pristino more dicendi", tiene una estructura sintáctica que se inscribe dentro de las figurae per ordinem ${ }^{7}$ como la realizacion de un isócolon, ordenado antitéticamente para enfatizar contenidos semánticos contrapuestos. La oposición "no decir" ("diuturni silenti .. finem") - "decir" ("initium ... pristino more dicendi"), esta resaltada por el quiasmo que establece una vinculación entre ella y el elemento temporal marcado por el "hodiernus dies" y su anaforico "idem", que ocupam el centro de la oración y enmarcan el único verbo principal "attulit", que oficia como una suerte de gozne temporal.

Por otra parte, el tiempo ("hodiernus dies"), en tanto sujeto de la oración, aparece como el desencadenante del cambio producido en el plano del decir. Ese hodiernus dies, en efecto, termina ("finem") con el silencio del orador e inicia ("inituim") su decir.

En tanto y en cuanto el discurso mismo verifica la concreción de ese initium dicendi, el hodiernus dies, aunque designa el presente, no aparece como un presente durativo sino como una instancia puntual, como un corte, en la medida en que todo el sintagma se tiñe del valor a la vez puntual, perfectivo e ingresivo del perfecto attulit. Es necesario señalar que, en el Pro Marcello, el presente es, dentro de la categoría temporal, el tiempo privilegiado, com lo demuestra la recurrencia, a lo largo de todo el discurso, de los deicticos de presente: "hodiernus dies" (I 1), "hodierno die" (I 3), "hodierno die" (I 4), "hunc ... diem (IV 11), "hodierno ... die (IV 12), "hodie" (32), etc.

Este análisis de la estructura profunda ${ }^{8}$ del perlodo, nos lleva a proponer la presencia de dos núcleos semánticos: el tiempo y el decir del orador que, como veremos, organizan toda la oratio.

El decir del orador se encarna en su voz que considera restituida ("vocem... restitutam puto", Marc. I 2) por el perdón de Marcelo cuyo agente es Cesar, el interlocutor de este discurso. Este acto es expresamente designado por Cicerón como um signum ("... et his omnibus ad bene de omni re publica sperandum quasi signum aliquod sustulist. "Marc. I 2), el cual, en

2 - Cir. H. Lausberg, 1966, vol. I, p. 109

3 - Cfr. H. Lausberg, 1966, vol, I, p. 203

4 - Cir. H. Lausberg, 1966, vol. I, p. 205

5 - Cfr. H. Lausberg. 1966, vol. I, p. 205

6 - Por otra parte, en Clcerón, lo utile slempre debe ser juzgado en relación con lo honestum. Cfr. Off. III 2,7 a 3,13)

7 - Cfr. H. Lausberg, 1966, vol. II, p. $166 \mathrm{ss}$.

8 - Cfr. Jean Cohen, 1974. 
tanto signum es susceptible de ser interpretado y cargado de significación. El mismo orador se encarga de semantizar ese signo y orientar su decodificación cuando dice: “ $M$. enim Marcello vobis, patres conscripti, reique publicae reddito. non illius solum, sed etiam meam vocem et auctoritatem vobis et rei publicae [conservatam ac] restituram puto" (Marc. I 2). De este modo Cicerón deja sentado que el acto de César, realizado "in summa potestate" (Merc. I 1), debe ser interpretado como la restitución de su voz al senado y a la república, lo que significa al mismo tiempo la restitución de la auctoritas ${ }^{9}$.

Al respecto recordemos que vox y oratio son usado como sinónimos, mediante el recurso de la endladis, en el célebre pasaje del De oratore III 2,6: "Illa tamquam cycnea fuit divini hominis vox et oratio, quam quasi exspectantes post eius interitum veniebamus in curiam, ut vestigium illud ipsum, in quo ille postremum institisset, contueremur...". Esta sinonimia, por ota parte, se reitera dentro del corpus ciceronianum ${ }^{10}$.

A partir de la citada oración y considerando la relación significante/significado como constitutiva del signo, podemos trazer el esquema A:

\section{Marcello reddito}

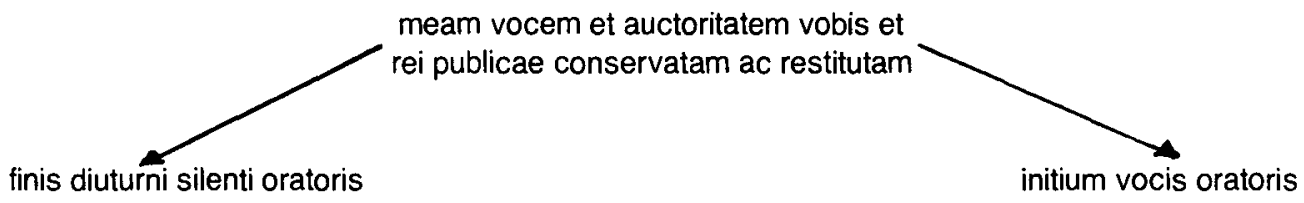

finis diuturni silenti senatus initium vocis senatus et rei publicae

vox oratoris

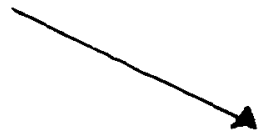
et rei publicae

vox et auctoritas senatus et rei publicae

Este esquema es el soporte de una aguda argumentación en la cual la voz del orador es la auctoritas y, forzando las instituciones mediante un notable juego retórico, el initium vocis ante Caesarem abre, en la realidad discursiva, una nueva instancia en la que se suman la auctoritas y la summa potesta "1. Asi leemos: "... cum summo consensu senatus, tum iudicio tuo gravissimo et maximo..." (Marc. 13) y "... de nobis quos in re publica tecum simul esse voluisti." (Marc. IV 19).

Esta configuración del presente afecta no sólo a los actos que en él se desarrollan sino también a los agentes de esos actos, pero, además, puesto que se lo predica como fin y principio, implica también por parte del orador, una determinada construcción del pasado y una expectativa del futuro, espacios para los cuales, segun veremos, nuevamente el orador oficia como intérprete.

\footnotetext{
9 - Cfr. Ronald Syme 1967, p. 44 ss.
}

10 - Crr. Cicerón, Sest. 23, 52.

11 - A propósito de este tema, dice A. Michel que "l'auctoritas est a Rome l'une de deux faces du pouvoir. L'autre s'appelle potestas, En effet, dans Padministration des affaires il y a deux temps, comme en toute, espece d'action. La reflexion doit précéder l'éxécution. Dans la decition mème, les deux elements son presents puisqu'il y entre une part de réalisation, mas aussi une déliberation. L'exécution est à Rome laffaire des maglstrats qui disposent pour celà de la potestas. Mais les conseils (consilium) qui préprarent l'éxécution, qui la controlent et la guident pendant sa mise en oeuvre, dolvent provenir de rauctoritas pour avoir du poids et de la valeur." (Michel, 1961, p. 61). Mas adelante (p. 62 ss.), Michel agrega que esta distribuición auctoritas/potestas, se ve alterada en tiempos de guerra y es entonces cuando le cabe um lugar preponderante a la oratoria pues el orator se transforma en el depositario de las instltuciones y la república. 


\section{EL PASADO}

El pasado que este hodiernus dies clausura no es monolftico ni puntual sino múltiple, tal qual aparece ya sugerido en el exordio. Hay, por lo pronto, un pasado del silencio y un pasado anterior a éste, el de la voz ("... meo pristino more dicendi." Marc. I 1 - "... meae pristinae vitae consuetudinem..." Marc. I 2).

Ahora bien, en la medida en que el acto del interlocutor, César, se ha realizado sobre un hecho del pasado, dicho acto supone e implica una cierta valoración de ese lapso temporal. Si este acto es presentado como um signum, también aqui sera el orador quien otorgue contenido a ese pasado, quien lo diseñe y lo construya, y lo hace de manera tal que hace compartir esa valoración a César: "Nam cum M. Marcellum deprecantibus vobis rei publicae consevavit; me et mihi et item rei publicae, mullo deprecante, reliquos amplissimos viros et sibi ipsos et patriae reddidit, quorum et frequentiam et dignitatem hoc ipso in consensu videtis, non ille hostis induxit in curiam, sed iudicavit a plerisque ignoratione potius et falso atque inani metu quam cupiditate aut crudelitate bellum esse susceptum." (Marc. V 13) y "... qui vero victor pacis autores diligit, is profecto declarat maluisse se non dimicare quam vincere." (Marc. $\vee 15$ ).

El pasado que construye el orador, está conformado por una serie de momentos en los cuales siempre aparece la relación vox oratoris-auctoritas-res publica, que subyace en el diseño del presente. Esos momentos son:

1. - LaPAX: es, desde luego, anterior a la guerra civil y esta caracterizada por la vigencia de la res publica, la auctoritas y la voz de orador (Marc. 1 1-2) ${ }^{12}$.

2. - EL BELLUM CIVILE: produce la destrucción de la república: "Non fuit recusandum in tanto civili bello, tanto animorum ardore et armorum, quin quassata res publica, quicumque belli eventus fuisset, multa perderet et ornamenta dignitatis et praesidia stabilitatis suae, multaque uterque dux faceret armatus quae togatus fiere prohibuisset." (Marc. VIII 24). En cuanto a la voz del orador, éste deja constancia de que habló a favor de la paz, pero su discurso fue repudiado: "Quod quidem meum consilium minime obscurum fuit; nam in hoc ordine integra re multa de pace dixi, et in ipso bello eadem etiam cum capitis mei periculo sensi." (Marc. $V$ 15) y "Quo quidem in bello semper de pace audiendum putavi, semperque dolui non modo pacem, sed etiam orationem civium pacem flagitantium repudiari." (Marc. V 14).

La transición PAX-BELLUM CIVILE, es obra ya del fatum, ya de los di immortales: "Omnes enim qui ad illa arma fato sumus nescio quo rei publicae misero funestoque compulsi, etsi aliqua culpa tenemur erroris humani, ab scelere certe liberati sumus." (Marc. $\vee 13$ ) y "... ut mihi quidem videantur di immortales etiam si poenas a populo Romano ob aliquod delictum expetiverunt, qui civile bellum tantum et tam luctuosum excitaverunt..." (Marc. V| 18). Como se desprende de las citas, la mencionada transición se encuadra dentro del sistema determinista, propio del estoicismo: el universo es un mecanismo perfecto controlado por el principio divino que, en último termino se identifica con él y cuya existencia se revela precisamente en esse ordem del cosmos. El mismo Cicerón, en De divinatione I 55,125, llama fatum a lo que los griegos denominaban heimarméne, esto es el orden y serie de causas. En el mismo pasaje expresa que el destino es la causa eterna de las cosas, por la cual no solo han ocurrido los hechos pasados y están ocurriendo los presentes, sino que también ocurrián los que están por venir.

12 - En tal sentldo, Cicerón en Rep. II 33,57 dice: "Id enim tenotote, quod initlo dlxi, nisi aequablils haec in ctvitate compensatlo sit ot luris et officil et munerls, ut et potestatis satis in magistrattlbus et auctoritatis in principum consilio ot libertatis in populo sith non posse hunc Incommutabllem rel publicae conservarl statum." 
3. - La VICTORIA CAESAFIS: esta señala el fin de la guerra y la implantación de la summa potestas, lapso que corresponde al "diuturni silenti".

La transición BELLUM CIVILE-VICTORIA CAESARIS es obra de la fortuna: "... erat obscuritas quaedam, erat certamen inter clarissimos duces: multi dubitabant quid optimum esset, multi quid sibi expediret, multi quid deceret, nonnulli etiam quid liceret. Perfuncta res publica est hoc misero fatalique bello; vicit is qui non fortuna inflammaret odium suum..." (Marc. X 30-31). Entre los varios significados de la palavra fortuna, liro Kajanto (Kajanto, p. 503-557) considera que, en sus obras filosóficas, Cicerón difine la fortuna como azar, aunque "In some of his ethical works, however, fortuna is more than a mere chance. It appears as a power beyond human control. Thus in the "Tusculans Disputations" he makes much of the antithesis virtus-fortuna, which is defined as "domina rerum... et externarum et ad corpus pertinentium" 5.25. According to Cirero, she is inferior to the human spirit, i.e. to virtutes, $2.30 ; 3.36 ; 5.2 ; 5.17$; to rutio, 2.11 ; to animus: 3.78 ; to consilium 5.25."

Esta oposición entre virtus y fortuna, se pone de manifiesto em el Pro Marcello VI 19: "Quare gaude tuo isto tam excellenti bono et fruere cum fortuna et gloria, tum etiam natura et moribus tuis, ex quo quidem maximus este fructus iucunditasque sapienti. Cetera cum tua recordabere, etsi persaepe virtuti, tamen plerumque felicitati tuae gratulabere; de nobis, quos ire publica tecum simul esse voluisti, quotiens cogitabis, totiens de maximis tuis beneficiis, totiens de incredibili liberalitate, totiens de singulari sapientia cogitabis; quae non modo summa bona, sed nimirum audebo vel sola dicere. Tantus este enim splendor in laude vera, tanta in magnitudine animi et consili dignitas, ut haec a virtute donata, cetera a fortuna commodata esse videantur." Sin embargo, su doble condición de suasio y laudatio, hace que, en este discurso, no sea posible determinar un único significado para la palavra fortuna.

De esta configuración del pasado, se deduce que la guerra civil fue obra de la fatalidad el designio divino, que ambos bandos tuvieron igtiál comportamiento y que el triunfo se debió a la fortuna y no al predominio de la mejor causa sobre la peor. Por lo tanto, no hay jueces ni culplabes, sino simplemente vencedores y vencidos. De este modo, la figura del iudicium, con la cual se designa el acto de Cesar, desaparece como tal pues los supuestos reos, es decir los partidorios de Pompeyo, no han cometido para con la república, ningún crimen que no haya cometido el mismo juez, César. El único juez posible es, en consecuencia, la república, cuya voz se arroga el orador. Esto se ve con toda claridad en el texto, pues, al final de todo el planteo, el orador no habla ya de iudicium sino de consilium: "... nisi belli civilis incendium salute patriae restinxeris, ut illud fati videatur fuisse, hoc consili." (Marc. IX 29). Asi pues, y a pesar de la salvedad hecha a propósito de los distintos significados de la palabra fortuna, no podemos dejar de recordar aquí la diferencia entre fortuna y consilium que aparece en el De re publica, respecto del origen de la grandeza de Roma: "... intellegesque non fortuito populum Romanum sed consilio et disciplina confirmatum esse nec tamen adversante fortuna." (II 16,30).

Tal como lo presenta Cicerón, no es la victoria lo que clausura el pasado sino el acto de César o, más exactamente, el significado político que le confiere el orador, el cual transforma a César de vencedor en gobernante pues la victoria es un hecho individual, en tanto que la restitución de la auctoritas es un hecho institucional. Asi Cicerón dice a César a propósito de su victoria: "Satis, si ita vis, fortasse naturae, addo etiam, si placet, gloriae at, quod maximum est, patriae certe parum" (Marc. VIII 25).

El estado de cosas que, en el universo discursivo, inicia este gesto, define una NOVA $P A X$ que se encadena con el pasado por medio del acto que lo clausura y lo hace en un doble sentido: clausura la guerra y tambien clausura el antiguo régimen republicano e instaura otro nuevo in summa potestate que, sin embargo, a traves de la vox restituta, mantiene la res publica. Por esta razón, el hodiernus dies, señala un verdadero initium. 
Podemos trazar el esquema $B$ :

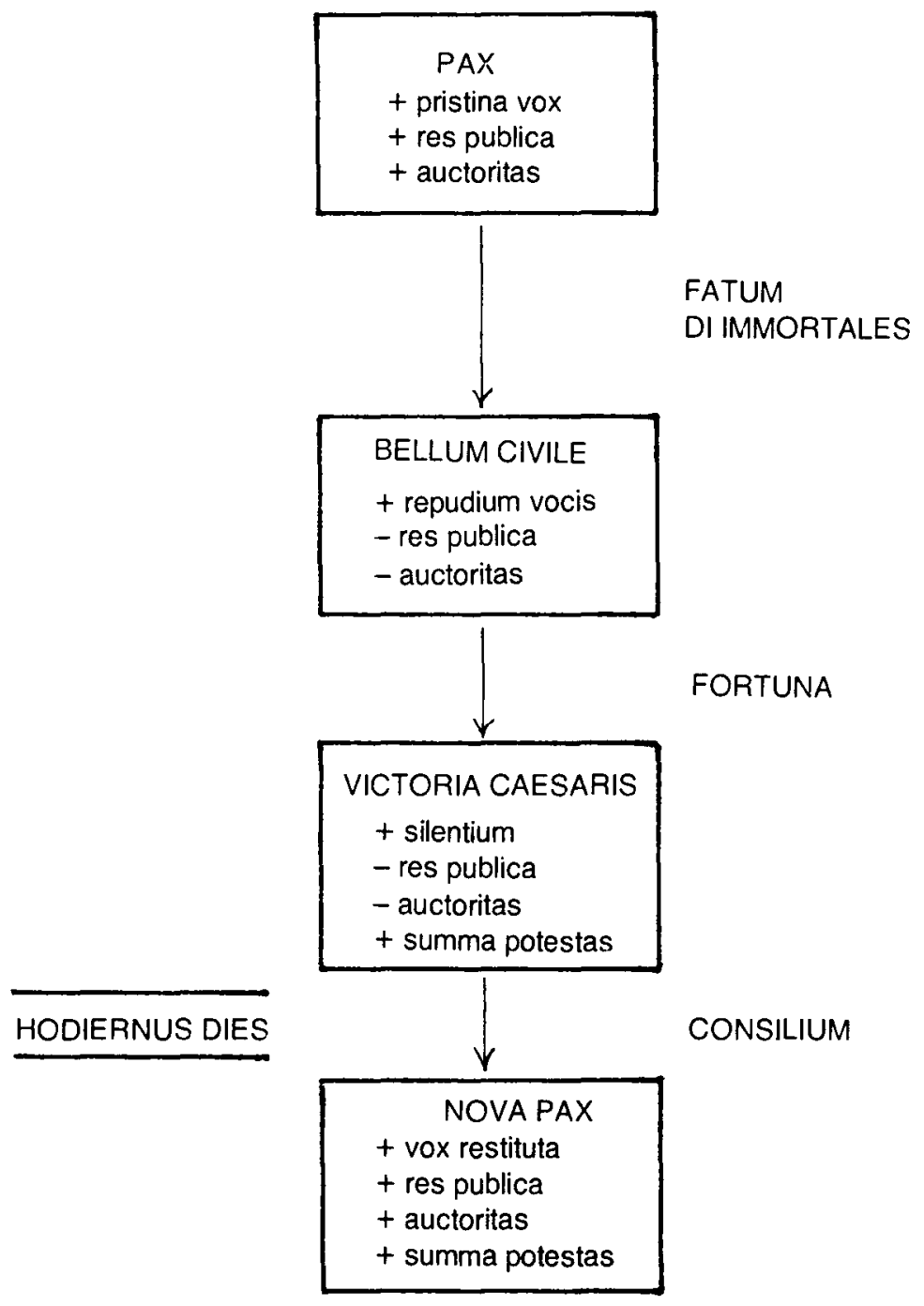

\section{EL FUTURO}

En cuanto al futuro, el mantenimiento del nuevo ordem, definido como la convivencia del senado y la summa potestas de César, es algo por hacer y el responsable es el mismo César, en virtud de la potestas: "Quase quidem tibi nunc omni bella volnera sananda sunt, quibus praeter te mederi nemo potest" (Marc. VIII 24); "Haec igitur tibi reliqua pars est, hic restat actus, in hoc elaborandum est ut res publica constituas..." (Marc. IX 27).

Esa misma institución, que ahora debe reconstruirse y mantener se, será la que juzgará sus actos. De este modo, César se transforma para el futuro en un reo que será juzgado no ya por su fortuita victoria, sino por sus actos responsables y voluntarios del tiempo de paz. El juez será la urbs, haec urbs, esto es la misma Roma, encamada en la voz del orador: "Sed nisi 
haec urbs stabilita tuis consiliis et institutis erit, vagabitur modo tuum nomen longe atque late, sedem stabilem et domicilium certum non habebit. Erit inter eos etiam qui nascentur, sicut inter nos fuit, magna dissensio, cum alii laudibus ad caelum res tuas gestas efferent, alii fortasse aliquid requirent, idque vel maximum, nisi belli civilis incendium salute patrie restinxeris, ut illud fati videatur fuisse, hoc consili. Servi igitur eis iudicibus qui multis post saeculis de te iudicabunt et quidem haud scio an incorruptius quam nos, nam sine amore et sine cupiditate et rursus sine odio et sine invidia judicabunt." (Marc. IX 29).

Si la mansuetudo y la clementia llevaron a Cesar a no hacer uso de sus derechos de vencedor, ahora es otra la virtud que se espera de él: la sapientia. En este contexto, las dos primeras corresponden al pasado de la victoria que, en el decir del orador, el mismo César ha clausurado. La tercera, al futuro de la pax, que él mismo ha inaugurado. Las relaciones que hemos señalado están claramente anticipadas en el exordio: "Tantam enim mansuetudinem, tam inusitatam inauditamque clementiam, tantum in summa potestate rerum omnium modum, tam denique incredibilem sapientiam ac paene divinam tacitus praeterire nullo modo possum." (Marc. I 1). Lo que en el pasado se predicó como virtudes, ahora son deberes que la institución reclama ${ }^{13}$.

En este sentido, en el De officiis I 34,124 Cicerón dice: "Est igitur proprium munus magistratus intellegere se gerere personam civitatis debereque ejus dignitatem et decus sustinere, servare leges, iura discribere, ea fidei suae commissa meminisse." Tales son los deberes que le son exigidos a César en el Fro Marcello VIII 23: "Omnia sunt excitanda tibi, C. Caesar, uni, quae iacere sentis belli ipsius impetu, quod necesse fuit, perculsa atque postrata: constituenda iudicia, revocanda fides, comprimendae libidines, propaganda suboles, omnia quae dilapsa iam diffluxerunt severis legibus vincienda sunt." Estos deberes som propios de la condición del togatus, el qual debe proseer virtudes clvicas que no son inferiores a la militares, tal como leemos en el De officiis: "Sunt igitur domesticae fortitudines non inferiores militaribus in quibus plus etiam quam in his operae studique ponendum est." (I 22,78)

Sin embargo, y a pesar del fundamento institucional de todo este planteo, donde la suasio llega a su máxima explicitación, poniendo en juego uno de los affectus que le son propios - el metus - es en el VII 21 del Pro Marcello, donde dice: "Nunc venio ad gravissimam querelam et atrocissimam suspicionem tuam, quae non tibi ipsi magis quam cum omnibus civibus, tum maxime nobis, qui a te conservati sumus, providenda est; quam etsi spero falsam esse, numquam tamen extenuabo: tua enim cautio nostra cautio est, ut, si alterutro peccandum sit, malim videri nimis timidus quam parum prudens... An, si nihil tui cogitant sceleris, cavendum est ne quid inimici? Qui? Omnes enim qui fuerunt aut sua pertinacia vitam amiserunt aut tua misericordia retinuerunt, ut aut nulli supersint de inimicis aut qui fuerunt sint amicissimi."

En la oratio, la conciliación de la summa potestas y la auctoritas senatus, hace su presentación final como un pacto por el cual las partes se ligan en el recíproco deber de velar la una por la otra para restaurar la república: "Quare omnes te, qui haec salva esse volumus, et hortamur et obsecramur ut vitae, ut saluti tuae consulas, omnesque tibi, ut pro aliis etiam loquam quod de me ipso sentio, quoniam subesse aliquid putas quod cavendum sti, non modo excubias et custodias, sed etiam laterum nostrorum oppositus et corporum pollicemur." (Marc. X 32) y "... nam laetari omnis on ut de unius solum, sed ut de omnium salutem sentio." (Marc. XI 33) ${ }^{14}$.

A partir del análisis efectuado, creemos estar en condiciones de concluir que la laudatio Caesaris no es aqứ más que un recurso del que hábilmente echa mano el orador para enmascarar una suasio que, por momentos, se torna una exhortación y hasta un condicionamiento. El Pro Marcello construye una realidad politica en tanto se ocupa de la organización institucional del poder y establece el rol que en ella tienen el orador y su interlocutor, César, los que representan, respecitivamente a los dos elementos constitutivos de ese nuevo estado de cosas: la 
auctoritas senatus y la summa potestas. Asf, como muy bien señala A. Michel (Michel, 1961, p. $622)$, el orador, delante del tirano, elige el rol de mentor filosófico y no renuncia a ser el representante de la sabidurla. Seguramente, en el espiritu de Ciceron subyacen las palabras proféticas que, en el año 49 aC. escribió a su amigo Atico, a propósito de César: "Corruat iste necesse est aut per advesarios aut ipse per se, quis quidem sibi est adversarius unus acerrimus" (Att. X 8,8).

\section{RESUME:}

Le Pro Marcello est souvent vu par la critique comme un acte d'obséquiosité de Cicéron devant César si bien qu'il se trouve inscrit dans le genus demonstrativum. L'analyse que l'on a effectué de ce texte, permet de demontrer que, dans ce discours, la laudatio Caesaris est un recours ayant pour but d'attirer l'attention et la bienveillance de César. Ce discours s'inscrit dans le genus deliberativum, plus précisément, dans la suasio. Le contenu et l'organisation de cette suasio repond au lien étroit et indissoluble existant dans la pensée de Cicéron entre son métier d'orateur, d'homme politique et de penseur.

\section{REFERËNCIAS BIBLIOGRÁFICAS}

CICERON, De officiis. (Quartum recognovit C. Atzert). Lipsiae: B. G. Teubneri, 1963.

-. De oratore. (Recognovit brevique adnotatione critica instruxit A. S. Wilkins). Oxoni: Typographeo Clarendoniano, 1951.

. De re publica. (Librorum sex quae manserunt sextum recognovit K. Ziegler). Lipsiae: B. G. Teubneri., 1964.

- Epistuale ad Atticum. Pars ii (9-16). (Recognovit brevique adnotatione critica instruxit $L$. C. Peuser). Oxoni: Typographeo Clarendoniano.

- Pour Marcellus - Pour Ligarius - Pour le roi Dejotarus (texte etablie et traduit par Marcel Lob). Paris: Les Belles Lettres, 1952.

COHEN, J., Teorla de la figura. In: Investigaciones retóricas // Buenos Aires: Tiempo Contemporáneo, s/d.

GUILLEMIN. A, Cicerón entre le génie grec et le mos maiorum, $R E L, 33$, p. 217 ss., 1955.

KAJANTO, I., Fortuna, ANRW II 17 1, p. 503-557.

LAFFRANQUE, M., Poseidonios d'Apamee. Essai du mise au point. Paris: P.U.F., 1964.

LAUSBERG. H., Manual de retórica literaria. Madrid: Gredos, 1966, 3 vol.

MICHEL, A., Humanisme et anthropologie chez Cicéron, REL, 62, p. 128-142, 1984.

. Rhétorique et philosophie chez Cicéron. Paris: 1961.

PERRET, J., A propos du Second Discours de Crassus. REL, 24, p. 169-189. 1946.

POHLENZ, M., La Stoa. Storia di un movimiento spirituale (Trad. de Ottone De Gregorio). Florencia: La Nuova Italia, 1967.

SYME, R., La révolution romaine. Paris: Gallimard, 1967. 